\title{
ENCOURAGING REFLECTION ON GENDER BIAS IN DESIGN EDUCATION
}

\author{
May Helen LILLEGÅRD, June Kyong TRONDSEN and Casper BOKS \\ Department of Design, NTNU Norwegian University of Science and Technology
}

\begin{abstract}
Gender stereotypes still dominate modern society, despite of an ongoing shift of ideas and ideals relating gender roles. Whilst design impacts our perceptions on gender roles, today's design education lacks the tools to help design students reflect upon the topic from different perspectives, and to reflect on their own likelihood to gender stereotype. This paper summarizes insights from a literature review, addressing terminology, the evolution of gender roles, the current status of gender bias in design, and current solutions, tools, and mindsets for addressing it. Based on these insights, this paper considers various approaches to introduce the topic in design education and proposes a workshop about gender bias in design as a practical yet effective way to start making up for this lack.
\end{abstract}

Keywords: Design practice, gender roles, gender system, stereotypes, bias, behaviour

\section{INTRODUCTION}

Today, we recognize a shift in gender roles and values in the modern society. Boundaries are being pushed as feminists are demanding equality, the voice of the queer is rising, and medical practice allows sex reassignment surgery. Simultaneously, the ideas and ideals of the masculine man and the feminine woman are still deeply integrated into our society and mindset and manifested through design. Our surroundings are filled with products, services, messages, and spaces expressing and manifesting the gender-related expectations in society. As consumers, we are subconsciously accepting images, ideals and ideas which manifest and confirm the social values and norms associated with the binary, heteronormative genders, man, and woman. This concept is described as 'gender roles' and normally represents two antipodes: the masculine male and the feminine female [1]. In other words, men are presumed to appear and behave masculine, whereas the opposing, feminine characteristics, are associated with women [2]. Consequently, behaviour associated with one gender is considered inappropriate for the other [1], thus contributing to the development of taboos and stigmas. From the early traces of gender segregation until today, gender roles have developed and shaped our perception of what it means to be a man or a woman. This has developed and translated into separated gender roles, evident through our preconceptions, expectations, and expressions, shaping and being shaped by the products, the space, and the vision we design. Knoll et al. [2] argue how such associations contribute to creating stereotypes, lacking sensitivity in reflecting variety in behaviour of and towards genders. These traditional gender roles are being maintained by materialism and capitalism, guiding design products, services and thinking. How design habitually exploits the concept of masculine men and feminine women is especially made evident in the product language of products. When put into society, such artefacts and systems communicate behaviours and expectations based on gender. Consequently, many are left out or restricted in opportunities and choices.

This paper intends to put the challenge of gender bias in design on the agenda, by exploring how designers are, and possibly can be better enabled to make conscious choices and take responsibility for the consequences of these. To do so, they need to become aware of the challenge concerning gender bias in design, while being encouraged to utilize their knowledge in practice. After further introducing the topic, this paper review existing tools and mindsets for educating designers in the role of gender bias in design and proposes a workshop format to this end. 


\section{TERMINOLOGY}

\subsection{Biological context}

There is a distinction between the term's 'sex' and 'gender' in literature. 'Sex' refers to the biological factors separating male and female, whereas 'gender' is more often used when speaking of sociological and psychological factors [3]. However, the latter is exposed to confusion with 'sex', as it is a constantly evolving term, defined by name, sexuality, external and internal genitalia, chromosomes, and genes [4]. The biological term 'sex' categorizes people by their physical attributes and mechanisms [3]. Grounding in the reproductive functions, where male and female are considered the two main categories, this is often referred to as the 'binary gender system'. However, modern research argues for a new way of conceptualizing sexes, by describing gender as a spectrum, with male and female as extremes [4]. The spectrum model includes non-binary sexes and genderqueers, such as intersex and transgender, and induces sex and gender studies.

\subsection{Social context}

Speaking of 'gender' in a social context, more ambiguous factors are accounted for. Originating from the biological understanding, gender refers to social roles, meaning characteristics or attributes associated with and expected from a particular sex [3]. This system, where the biological separations of the sexes have been brought onto social processes, creates a structure of social relations [5] on a symbolic, structural, and individual level [6]. Bem [1] explains how the gender structure is a set of polarized characteristics, being either masculine or feminine, strongly associated with being male or female, respectively [2]. Furthermore, Knoll et al. [2] argue how such associations contribute to creating stereotypes, lacking sensitivity in reflecting variety in the behaviour of and towards genders. Butler [7] argues for a more fluid gender theory, with the existence of many possible categories of gendered and sexual practices, beside the binary definitions. In other words, gender identity depends on, amongst others, age, ethnicity, sexual orientation/identity, social status and/or (dis)ability [8]. Nevertheless, literature reveals that the perception of two main, opposing genders, being imposed with distinct gender roles, are deeply integrated into most Western societies.

\section{EVOLUTION OF GENDER ROLES}

Whether speaking of the biological 'sex' or the social 'gender', society consciously and subconsciously imposes different sex and gender roles onto people. Stereotypical gender roles are collections of norms and attributes based on the heteronormative, binary genders. These beliefs are stated to distinguish women from men [9] and are often influencing our thoughts, feelings, and behaviour. In a study of gender roles in a historical context, Hansen et al. [10] suggest the Neolithic Revolution is a major factor in the formation of modern gender roles. This revolution marks the transition from a hunter-gatherer society to an agricultural society. Further, their research presents how the societal contribution was more equally distributed amongst the sexes in the hunter-gatherer society [10]. As the agricultural society demanded more workforce, women were more often pregnant than their hunter-gatherer ancestors, leaving them with less time to take part in activities other than child-rearing [11]. Simultaneously, men provided for the family and society, resulting in the growth of patriarchal values [10], initiating the development of the 'separate spheres ideology' (SSI) in the 19th century. Since then, machines have surpassed the human workforce and the rise of feminism has progressively desegregated the sexes in society. With increased research and knowledge on sex and gender over the past 30 years, acceptance of variety and diversity has increased [2]. Nonetheless, present gender roles and norms of Western societies are bearing the mark of being shaped by the former segregation patterns [10].

As established values in society, the mindset of gender roles is criticized by many scientists and advocates in different fields. Bem [1] explained how expectations, behaviour, beliefs, thoughts, and preconceptions are affected by the concept of masculine men and feminine women. Additionally, Bem argues that behaviour that is not 'assigned' to the biological sex is considered problematic or taboo. Moreover, some state it promotes the idea of masculinity and male being the standard, while femininity and female are subordinates, whose purpose is to fulfil male heterosexual desires [6]. Consequently, being a man with feminine traits is regarded as more controversial than a woman with masculine traits [12]. 


\section{GENDER BIAS IN DESIGN}

The environment is constantly reminding us and influencing our perceptions on gender roles, reinforced by established systems and structures. Further, these told and taught ideas and ideals of gender and gender roles are passed onto our children [1]. Martin et al. [13] describe how the perception of gender roles develops in a series of four stages while growing up. The taught behaviour towards others, ourselves and products is reinforced by the environment we design and continues into adolescence and adult life [14]. The first stage concerns what children up to the age of four learn about the direct association between artefacts and the sexes, such as "cars belong to boys" and "dolls belong to girls" [13]. This behaviour is a clear consequence of how the separation principle is expressed through product language and design [6]. In the second stage, children at the age of four to six start understanding the associations relevant to their own sex [13]. Products targeted at girls promotes the expectation of girls to be beautiful, quiet, and caring, whereas toys targeted at boys create the assumption of boys being tough, smart, and logical. This correlates with gender-related products in general, where products for helpfulness and performance are associated with female and male characteristics respectively [6].

Around the age of eight, children move to the third stage, where associations relevant to the opposite sex are taught [13]. The gender stereotypes children are being exposed to, teach them how to behave, treat, and what to expect from others, based on assumptions about gender [14].

Despite the changes in gender roles over the past 30 years, traces of the gender system are to be found in design [15], where women and men are being perceived and depicted in stereotypical gender roles to promote products and services [2]. Eisend et al. [16] point out how this reinforcement of stereotypical values in society through designed products and services can lead to negative consequences. A prominent example of how design and gender roles are intertwined is the sex-segregated toilet which communicates a universal need for privacy between the sexes, rooted in the SSI where women were considered 'vulnerable' and should be spared from the public space, dominated by the 'vile' men. Moreover, the gendered segregation, based on the binary genders leaves people with another gender identity uncertain of where to go. However, the tendency to reproduce stereotypical values have led to a growth in criticism of the lack in sensitivity to depict variety and diversity in genders [2], resulting in for example Stalled!, a public restroom concept aiming to "register the complex, fluid and intersectional nature of race, class and gender in a way that meets the goals of social equity, diversity and inclusion." The criticism is also evident in product design, where for instance the exclusive fashion brand Gucci, launched a dress for men in their Fall Winter 2020 collection. Their intention was to disrupt "the toxic stereotypes that mould masculine gender identity".

\section{EXISTING SOLUTIONS AND MINDSETS}

Both scientific literature and design practice offer a number of methodologies and approaches focusing on inclusion and equality. Universal design, inclusive design, and design for all are just a few examples. Additionally, the development of strategies and methodologies specifically paying attention to gender inequality and inclusion is increasing. Table 1 lists five methodologies that address the relation between gender and design. It also includes four toolkits which aim to challenge the heteronormative mindset, although these are not explicitly addressing design. It should be noted that few of these account for gender fluidity as they mainly focus on equality between the binary genders.

A gap analysis suggests that these design approaches and toolkits have in common that they lack references to tools or guidelines on how to become aware of gender bias when designing, and how to address the complexity of the gender bias challenge. Designers need to become informed of how their practice is influenced by traditional values and economic forces, such that awareness of possible biases is raised and the consequences of these can be managed. When awareness is raised, existing tools and methodologies can be utilized in a controlled manner.

A lack of dedicated design tools does not mean that the topic of gender inclusion is not addressed in society. In areas other than industrial design, several examples of gender inclusivity to inspire designers can be found. Examples include gender inclusive classrooms, gender-inclusive recruitment, genderinclusive language and gender-inclusive architecture [3]. While these examples reveal progression in society, the appropriate question to ask may be whether design is keeping up with this pace, and how designers can become more in control of the implications of their work. 
Table 1. Overview of existing design approaches and solutions with attention to gender

\begin{tabular}{|c|c|c|c|}
\hline Methodology & Goal & $\begin{array}{l}\text { Gender } \\
\text { model }\end{array}$ & Gap \\
\hline $\begin{array}{l}\text { Gender-blind } \\
\text { design }\end{array}$ & $\begin{array}{l}\text { Disregarding gender as a factor in human interactions } \\
\text { (https://eige.europa.eu/thesaurus/terms/1157) }\end{array}$ & binary & $\begin{array}{l}\text { Does not recognize biological } \\
\text { differences between genders }\end{array}$ \\
\hline $\begin{array}{l}\text { Gender } \\
\text { mainstreaming }\end{array}$ & $\begin{array}{l}\text { Accounting for women's and men's interests and } \\
\text { concerns ([8]. }\end{array}$ & binary & $\begin{array}{l}\text { Does not explicitly account for } \\
\text { gender fluidity. No clear design } \\
\text { guidelines to create awareness }\end{array}$ \\
\hline $\begin{array}{l}\text { Gender neutral } \\
\text { design }\end{array}$ & $\begin{array}{l}\text { Avoiding gender stereotyping and association } \\
\text { (https://forty8creates.com/gender-neutral-design/) }\end{array}$ & binary & $\begin{array}{l}\text { Do not account for extreme } \\
\text { feminine and masculine } \\
\text { characteristics }\end{array}$ \\
\hline $\begin{array}{l}\text { International } \\
\text { Gender Design } \\
\text { Network (iGDN) } \\
\end{array}$ & $\begin{array}{l}\text { International initiative dedicated to put Gender and } \\
\text { Design on the agenda (http://genderdesign.org/about- } \\
\text { igdn/mission-and-objectives/) }\end{array}$ & $\begin{array}{l}\text { not } \\
\text { defined }\end{array}$ & $\begin{array}{l}\text { No tangible solutions to create } \\
\text { awareness in the design process }\end{array}$ \\
\hline $\begin{array}{l}\text { Gender in } \\
\text { design }\end{array}$ & $\begin{array}{l}\text { Integrating gender in design by providing toolkits with } \\
\text { comprehensive methods (http://genderindesign.com/.) }\end{array}$ & fluid & $\begin{array}{l}\text { Not efficiently creating } \\
\text { awareness of gender bias in the } \\
\text { design process }\end{array}$ \\
\hline $\begin{array}{l}\text { Inclusive } \\
\text { design: Mixing }\end{array}$ & $\begin{array}{l}\text { Methodology used to create all-inclusive public } \\
\text { restroom concept, (https://www.stalled.online/home) }\end{array}$ & fluid & $\begin{array}{l}\text { No design guidelines to utilize } \\
\text { the findings in future projects }\end{array}$ \\
\hline \multicolumn{4}{|l|}{ Toolkits } \\
\hline $\begin{array}{l}\text { Method kit for } \\
\text { equal places/ } \\
\text { gender equality }\end{array}$ & $\begin{array}{l}\text { Based on gender mainstreaming. Cards to discuss and } \\
\text { improve equality within organizations } \\
\text { (https://methodkit.com/shop/methodkit-for-equality/) }\end{array}$ & binary & $\begin{array}{l}\text { Focus on equality between } \\
\text { (binary) genders and is not } \\
\text { explicitly targeting designers }\end{array}$ \\
\hline $\begin{array}{l}\text { Gender equity } \\
\text { toolkit }\end{array}$ & $\begin{array}{l}\text { Used when designing for gender equality in workplace } \\
\text { (https://www.leylaacaroglu.com/portfolio/2016/12/16 } \\
\text { /gender-equity-toolkit) }\end{array}$ & binary & $\begin{array}{l}\text { Only considers leadership and } \\
\text { companies }\end{array}$ \\
\hline $\begin{array}{l}\text { Gender in } \\
\text { design toolkit }\end{array}$ & $\begin{array}{l}\text { Address the difference between sex, gender, and } \\
\text { intersectionality. A collection of critical questions, case } \\
\text { studies and design methods. }\end{array}$ & fluid & $\begin{array}{l}\text { No tangible solution/tool to use } \\
\text { for designers }\end{array}$ \\
\hline $\begin{array}{l}\text { Gender and } \\
\text { Security Toolkit }\end{array}$ & $\begin{array}{l}\text { For people working with/for others who are deprived } \\
\text { of liberty by integrating gender perspectives [18] }\end{array}$ & fluid & $\begin{array}{l}\text { Does not concern everyday } \\
\text { products and services }\end{array}$ \\
\hline
\end{tabular}

\section{TOWARDS AN INTERVENTION FOR EDUCATING DESIGNERS}

With the above in mind, the authors initiated a project aiming to develop an intervention educating designers on the role of gender bias in design and to create awareness about potential bias concerning the binary gender system and stereotypes. One way to do this would be to confront design students with the problems of (designing for) a binary gender model through critical design, for example utilize artistic methods, such as installations or campaigns, presenting the challenge in a dystopian or utopian way. Another way would be to encourage reflection by presenting a nuanced overview of the challenge. The latter was considered a more including concept, allowing design students to reflect upon the interplay between design and gender roles, and to find and develop their own values as designers. Initial research revealed that students generally expressed an understanding of the concept of gender bias and acknowledged that they themselves may be biased with or without realizing this but lacked the means to reflect over this, and to translate these reflections and resulting insights into their design practice.

Various educational concepts were evaluated. Developing an entire course was quickly dismissed due to the challenge of evaluating students in a course which has as main purpose to raise awareness and encourage reflection. Developing a new tool or adjusting existing ones or developing a game or a service were all considered to be too limited with respect to the information richness to be included for meaningful reflection and to avoid resorting to simple stereotyping. It was also considered to develop a set of guidelines, but because gender bias in design is a complex and comprehensive topic, it would be challenging to find the balance between too normative or biased, and too abstract or vague. Within the context of the project, it was decided to create something realistic which could be realized in the nearest future. As result, development of a workshop concept with the purpose of raising awareness of gender bias in design was concluded to be the most feasible to conceptualize. Workshops function as arenas for discussion and reflection upon complex topics, such as the relation between design and gender values and roles. Building on a combination of conveying information and practical tasks, students are able to understand the challenge in a historical and practical context. 


\subsection{Final workshop concept}

After several iterations, which are not discussed here because of space restriction, the final workshop concept consists of five parts alternating between theoretical and practical ways of learning and concluding with presentations and reflections from the tasks.

Part 1: Introduction [1 hour] consisting of two main elements:

- A warm-up, in-medias-res exercise [15 min] where students are first to design/sketch two bags, one targeted at women and one targeted at men, then to describe the functionality, attributes, and aesthetics of their designs, and finally to reflect over how gender aspects affected their designs. This warm-up provides an immersive approach and starts creative, reflective, and critical thinking.

- An introduction of the gender bias in design challenge [45 min], presented by an expert in the field, focusing on

- Gender stereotypes and roles related to femininity and masculinity

- Historical context of gender roles and gender (binary and gender fluidity), including SSI and different factors affecting gender roles, from a political, feminist, cultural and capitalistic perspective (as briefly addressed in section 3 of this paper)

- How we learn about gender roles in childhood (extreme examples of gender bias)

- Contemporary context of gender roles and gender, and its expression through design (examples of products and services).

Part 2: Analysing products [1,5 hours]. This second, practical task builds on the previous theory. Here, the students explore and analyse different products (images of feminine, masculine, and neutral products and services are provided) to find how the intentions of the designs might be gender-biased, and through what types of visual cues. The purpose of the task is to connect theory and practice, experience gender bias in context, trigger reflection and discussion, using the theory from part 1.

Part 3: Designer's responsibility [ $30 \mathrm{~min}$ ]. The last theory part concerns the responsibility of designers in this challenge. The purpose is to learn how bias surrounds us - the extent of it and what it does, as well as the consequences of not being aware of this. The presentation focuses on awareness of affordances and what design expresses, learning examples of where gender design has an impact on users, stories, and experiences with gender-biased design and how/why they fail/succeed, and finally on how and why designers should be more critical and challenge gender bias.

Part 4: Redesign [3 hours]. This part consists of two tasks. First, students are asked to pick two of the designs from part 2 and change their product language from masculine to feminine and vice versa. Thereafter they reflect on what has changed in terms of binary stereotypes, and how this is conveyed in the overall impressions of the designs convey. Second, they are challenged to redesign one of the designs such that it is no longer gender-biased and argue from different viewpoints why this is the case.

Part 5: Presentation [1,5 hours] is devoted to short 7-minute presentations reflecting on the practical exercises, focusing on takeaways and findings from the workshop.

\subsection{Testing and evaluation}

Because of the pandemic and limited access to students, the final concept could not be extensively tested and had to be compressed in time and number of participants. In the final testing round, these included master and PhD students in Industrial Design and Psychology. Rather than a full record of the testing, a number of observations from the test are shared here. What seemed to work well is how the workshop was an eye-opener, even for participants who already stated to be aware of the issue but had not explicitly reflected over it. They became very aware of their lack of ability to conceptualize what a man and a woman are, other than through stereotypes. Throughout the workshop, the participants showed ability to reflect upon the challenge from different perspectives through fruitful discussions and assess how their professional design practice may (or not) be influenced by it. They expressed how they were more aware of the negative consequences of gender stereotyping on women but realized throughout the workshop how this applied to men as well. Other stated takeaways for future design practice included reflections on how gender bias occurs in design, a feeling of better control of the effects of gender bias when designing, reasons for why (not) design should target a specific gender, more reflected views on gender roles in design, and a lot of questions and curiosity. It was noted that participants seemed to hold similar values; ideally, participants would have been more diverse in values and opinions on this topic, potentially leading to discussions providing greater insights of and reflections upon various perspectives. 


\section{REFLECTIONS}

Gender bias in design is a wicked problem, and in the process of trying to address such a problem, new and more complex questions arise. Instead of ignoring them, we should recognize them to handle them accordingly. The proposed workshop can be a useful instrument for achieving this, but it is still mostly a reflective one. To address this wicked problem, further knowledge is required; hence, further research is proposed addressing questions such as: Where in the design process does gender bias start to occur? How to distinguish between gender and sex in design, as in, when to focus on biological and societal contexts? To what extent are functionality and aesthetics intertwined? What are the positive and negative effects of gender bias on the well-being of different segments of users? Better insights on these questions and their answers will be food for further development of educational approaches to address gender in design, beyond the proposed workshop format. For now, this format has received interest from both students, researchers, teachers, and professional designers in the industry, and will hopefully contribute to reflection among those exposed to it. With a growing culture for online collaboration tools, there are many further possibilities in experimenting with the current format. Since the workshop main focus is discussion and reflections, rather than physical output, arranging it through platforms such as Teams and Zoom, with group discussions in designated so-called 'rooms', could give a similar effect. The experience of arranging such workshops and using Miro proved how easy, yet effective it is.

\section{REFERENCES}

[1] Bem, S. L. (1974). The measurement of psychological androgyny. Journal of consulting and clinical psychology, 42(2), 155.

[2] Knoll S., Eisend M., and Steinhagen J. (2011). Gender roles in advertising: Measuring and comparing gender stereotyping on public and private TV channels in Germany. International Journal of Advertising, 30(5), 867-888.

[3] Terraza H., Orlando M. B., Lakovits C., Janik V. L., and Kalashyan A. (2020). Handbook for Gender-Inclusive Urban Planning and Design.

[4] Slagstad K. (2018). Not both genders, but all genders. Tidsskriftet Den Norske Legeforening, November 2018. doi: 10.4045/tidsskr.18.0888

[5] Connell R. and Pearse R. (2009). Gender: in world perspective. Polity Press, Cambridge, UK.

[6] Ehrnberger K., Räsänen M., and Ilstedt S. (2012). Visualising gender norms in design: Meet the mega hurricane mixer and the drill dolphia. International Journal of design, 6(3).

[7] Butler J. (2011). Gender trouble: Feminism and the subversion of identity. Routledge.

[8] Council of Europe. (n.d.). What is gender mainstreaming? Gender Equality. Retrieved February 15, 2021, from https://www.coe.int/en/web/genderequality/what-is-gender-mainstreaming

[9] Ashmore R. D. and Del Boca F. K. (1981). Conceptual approaches to stereotypes and stereotyping. Cognitive processes in stereotyping and intergroup behaviour, 1, 35.

[10] Hansen C. W., Jensen P. S., and Skovsgaard C. V. (2015). Modern gender roles and agricultural history: the Neolithic inheritance. Journal of Economic Growth, 20(4), 365-404.

[11] Diamond J. (1987). The worst mistake in the history of the human race. Discover Magazine, May 1987.

[12] Adler P. A., Kless S. J., and Adler P. (1992). Socialization to gender roles: Popularity among elementary school boys and girls. Sociology of education, 169-187.

[13] Martin C. L., Wood C. H., and Little J. K. (1990). The development of gender stereotype components. Child development, 61(6), 1891-1904.

[14] Witt S. D. (1997). Parental influence on children's socialization to gender roles. Adolescence, 32(126), 2

[15] Rommes E., Bos M., and Geerdink J. O. (2011). Design and Use of Gender Specific and Gender Stereotypical Toys. International Journal of Gender, Science \& Technology, 3(1).

[16] Eisend M., Plagemann J., and Sollwedel J. (2014). Gender roles and humour in advertising: The occurrence of stereotyping in humorous and non-humorous advertising and its consequences for advertising effectiveness. Journal of advertising, 43(3), 256-273.

[18] DCAF, OSCE/ODIHR, UN Women (2019). Places of Deprivation of Liberty and Gender. Gender and Security Toolkit, Geneva: DCAF, OSCE/ODIHR, UN Women. 